$\underline{\text { Submitted to Journal of Alloys and Compounds (February 2017) }}$

\title{
Orientation imaging microscopy and microhardness in a ZK60 magnesium alloy processed by high-pressure torsion
}

\author{
Seyed Alireza Torbati-Sarraf ${ }^{1}$, Shima Sabbaghianrad ${ }^{1, *}$, \\ Roberto B. Figueiredo ${ }^{2}$, Terence G. Langdon ${ }^{1,3}$ \\ ${ }^{1}$ Departments of Aerospace \& Mechanical Engineering and Materials Science, \\ University of Southern California, Los Angeles, CA 90089-1453, U.S.A. \\ ${ }^{2}$ Department of Materials Engineering and Civil Construction, \\ Universidade Federal de Minas Gerais, Belo Horizonte, 31270-901 MG, Brazil \\ ${ }^{3}$ Materials Research Group, Faculty of Engineering and the Environment, \\ University of Southampton, Southampton SO17 1BJ, UK \\ *Corresponding author. E-mail address: ssabbagh@usc.edu Tel: +1 (213) 7404342
}

\begin{abstract}
An extruded ZK60 magnesium alloy was processed by high-pressure torsion (HPT) at room temperature for up to 5 turns under a constant compressive pressure of $2.0 \mathrm{GPa}$ with a rotation speed of $1 \mathrm{rpm}$. This processing produced an average grain size of $\sim 700 \mathrm{~nm}$. The grain size distributions and textures were examined by electron backscatter diffraction (EBSD) and this revealed some multi-modality in the microstructure at different stages of straining with fractions of both coarse grains and ultrafine grains. EBSD analysis at the mid-radius positions of unprocessed and HPT-processed materials revealed a gradual evolution from a prismatic $\{10 \overline{1} 0\}$ fiber to an ultimate basal $\{0001\}$ fiber texture with the $c$-axis parallel to the normal direction. The majority of grain boundaries had misorientations larger than $15^{\circ}$ throughout the processing. The strain hardening tended towards a reasonable hardness homogeneity with a hardenability exponent, $\eta$, of 0.07 up to strains of $\sim 20$ and with a subsequent hardness saturation at $\mathrm{Hv} \approx 125$.

Keywords: high-pressure torsion, hardenability, magnesium alloy, texture, ultrafine-grained materials.
\end{abstract}




\section{Introduction}

Magnesium is the lightest structural metal which is abundantly available. Furthermore, outstanding mechanical properties, including high specific strength and high elasticity, has made $\mathrm{Mg}$ and its alloys promising candidate materials for aerospace [1] and automotive [2] applications over the last two decades. Magnesium is also now receiving more attention in biomedical engineering [3] and in portable electrical devices due to its recyclability and bioadaptability [4]. Nevertheless, the metal suffers from poor formability at ambient temperature due to the low symmetry in the hexagonal close-packed (hcp) crystal structure and the general limitation of slip to the basal planes. Attempts have been made to improve the ductility of $\mathrm{Mg}$ alloys by developing their superplastic properties $[5,6]$ and accordingly it is reasonable to anticipate that microstructural refinement of these alloys to the submicrometer level may provide a potential for achieving both high strength and reasonable ductility.

Conventional thermomechanical processing is generally used to achieve grain sizes of the order of a few micrometers. However, greater grain refinement may be achieved, to the submicrometer or even the nanometer level, by processing bulk metals using techniques incorporating the application of severe plastic deformation (SPD) [7-9]. Several SPD processes are now available but the most important are equal-channel angular pressing (ECAP) [10] where a rod or bar is pressed through a die and high-pressure torsion (HPT) [11] where a disk is subjected to a high pressure and concurrent torsional straining. In practice, HPT is especially attractive because it produces grains that are consistently smaller than in ECAP [12,13] and also with a higher fraction of grain boundaries having high angles of misorientation [14].

Several recent studies examined the microstructural evolution in fcc materials using electron backscatter diffraction (EBSD) imaging after SPD processing by ECAP and HPT [15- 
17]. In addition, there are limited reports on the microstructural and textural evolution in hcp materials such as $\mathrm{Mg}$ [18-20] and $\mathrm{Ti}$ [21,22] alloys after processing by ECAP or HPT. Very recent studies examined the microstructural evolution in the ZK60 Mg alloy using optical and electron microscopy [23-27]. Accordingly, the present investigation was initiated to provide the first microstructural and textural investigation by EBSD imaging of a ZK60 alloy processed by HPT. In addition, the microhardness evolution was also examined both to determine the significance of work hardening by measuring the hardenability exponent of the alloy and also to investigate the potential for developing a saturation hardness after processing to high strains.

\section{Experimental material and procedures}

Rods of a ZK60 magnesium alloy (Mg-5.5 wt.\% Zn-0.5 wt.\% Zr) were obtained in an extruded condition with diameters of $10 \mathrm{~mm}$. Disks were sliced perpendicular to the extrusion direction with thicknesses of $\sim 1.2 \mathrm{~mm}$ and then carefully ground on both sides using abrasive papers to give final thicknesses of $\sim 0.82 \pm 0.02 \mathrm{~mm}$.

The HPT processing was conducted under quasi-constrained conditions [28,29] using an HPT facility containing a rotating lower anvil and a stationary upper anvil. Both the lower and upper anvils contained central spherical depressions with depths of $0.25 \mathrm{~mm}$ and diameters of 10 mm. The HPT processing was performed at room temperature (RT) using an applied pressure, $P$, of $2.0 \mathrm{GPa}$ and a constant rotation speed of $1 \mathrm{rpm}$ through total numbers, $N$, of 1/8, 1/4, 1/2,1, 2 and 5 revolutions. Post-inspection of the disks after HPT showed no damage or cracking and there was no evidence for any slippage during the processing [30].

Microstructural observations were conducted on the processed samples at the mid-radius positions of the disks and these observations were performed close to the original surface of each sample. A JEOL IB09010CP ion beam cross-sectional polishing facility was used to polish the 
samples at an operating voltage of $6 \mathrm{kV}$ for 5 hours. An analytical field emission scanning electron microscope (SEM) JEOL JSM-7001F was used at an operating voltage of $7 \mathrm{kV}$ with EBSD and orientation imaging microscopy (OIM) utilized to record the data. Figure 1 shows the position at which the disks were ion polished by the cross-sectional polishing facility, where the directions labeled ND, TD and RD correspond to the Normal (torsion axis), Tangential and Radial Direction, respectively. As shown by the inset in Fig. 1, the shear direction is parallel to TD. The step size was $0.1 \mu \mathrm{m}$ and the images were cleaned up using grain confidence index (CI) standardization and neighbor CI correlation. Low-angle grain boundaries (LAGBs) were defined as boundaries having misorientation differences between adjacent measuring points of $2^{\circ}-15^{\circ}$ and high-angle grain boundaries (HAGBs) were defined with misorientation differences of more than $15^{\circ}$. The inverse pole figures in the EBSD images were measured from the semi-oval area of the sample in the TD-RD plane as shown in Fig. 1.

Microhardness measurements were carried out on the upper surfaces of the HPTprocessed disks along randomly selected diameters. All samples were polished to achieve mirror-like surfaces by removing a layer of up to $\sim 0.1 \mathrm{~mm}$ from each surface before recording the measurements. The Vickers microhardness values, Hv, were obtained at room temperature using an FM-1e microhardness instrument equipped with a Vickers indenter using a load of 100 gf with a dwell time of $10 \mathrm{~s}$ for each separate measurement. The indentations were conducted along randomly selected diagonal lines on each disk with the points separated by incremental distances of $0.3 \mathrm{~mm}$. The hardness values were recorded as the average of four positions formed in a cross-shape around each selected point at distances of $0.15 \mathrm{~mm}$. A detailed description of this method was given earlier [31]. 


\section{Experimental results}

\subsection{Microstructural evolution}

Figure 2 provides a montage of image quality (IQ) micrographs of the unprocessed extruded material prior to HPT followed by $1 / 2,1$ and 5 turns of HPT in the mid-radius positions of the disks and Fig. 3 gives the corresponding grain size distributions for each condition shown in Fig. 2. Although the average grain size for the extruded sample was estimated as $\sim 5 \mu \mathrm{m}$, it should be noted that some relatively large grains were also present in the extruded material as noted in an earlier report [24]. Observations on the microstructural changes occurring with SPD processing showed a gradual change in grain size from the extruded condition to an ultrafinegrained structure after 5 turns of HPT. Processing through 1/2 and 1 turn of HPT as shown in Fig. 2(b) and (c) gave areas with aggregates of small grains but also some areas with relatively coarser grains. By contrast, after processing by 5 turns of HPT most of the grains were significantly refined although a small fraction of coarser grains was present in the microstructure.

The distributions of grain sizes plotted in Fig. 3 show that all grains were larger than 1 $\mu \mathrm{m}$ in the extruded condition with a peak in the distribution at $\sim 5 \mu \mathrm{m}$. Processing by $1 / 2$ and 1 turn gave finer grains with peaks in the distributions in the range of $\sim 1-2 \mu \mathrm{m}$. Processing by 5 turns gave an increase in the area fraction of fine grains and a peak in the distribution at $\sim 1 \mu \mathrm{m}$. For all experimental conditions, the grain size distributions are spread over about one order of magnitude of grain size. This shows that the grain size distributions in the ZK60 alloy tend to be heterogeneous for all conditions including after processing through 5 turns of HPT.

Table 1 provides further information on the grain sizes obtained from the EBSD analysis including details on the area fractions of exceptionally small grains. The evidence for a 
heterogeneity in the grain size distributions is consistent with earlier reports of bi-modalities in the grain size distributions in various magnesium alloys processed by HPT under pressures of 2.0 to $6.0 \mathrm{GPa}$ at room and elevated temperature [20,23-27]. At elevated temperatures the bimodal structure is generally associated with the formation of a necklace structure along the grain boundaries $[19,32]$ but necklace formation was not present after processing at room temperature either in this study or in earlier investigations $[25,33,34]$.

The number fractions of misorientation angles are shown in Fig. 4 for the as-received extruded condition and after processing by HPT through 1/2, 1 and 5 revolutions: all of these data correspond to the preferred next-neighbor misorientation distributions $[35,36]$ rather than the pixel to pixel misorientations. In Fig. 4 the solid curves represent the distributions of misorientation angles for an aggregate of randomly oriented hexagonal crystals where these curves were developed earlier using a Monte-Carlo method for AZ31 [37,38] and AM60 [39] magnesium alloys. This distribution corresponds to a basal fiber where the neighboring grains have the $c$-axis at angles lower than $30^{\circ}$, there is a maximum at $30^{\circ}$ and a cut-off value at $42.3^{\circ}$ [37]. Also shown in Fig. 4 are the conventional Mackenzie random distributions [40,41] where the distribution corresponding to a random aggregate of hexagonal crystals has a maximum of $90^{\circ}$ and a cut-off value of $93.84^{\circ}$. Inspection of Fig. 4 shows that the number fraction of misorientations between $85^{\circ}$ and $90^{\circ}$ rises after $1 / 2$ turn and this peak remains visible after 1 and 5 turns. After 5 turns there is also another peak at about $30^{\circ}$.

Table 2 provides a percentile analysis of the misorientation angles measured from Fig. 4 showing the individual fractions for HAGBs, LAGBs and angles of either $30^{\circ}$ or in the range of $85-90^{\circ}$. It can be seen from Fig. 4(a) that the as-received extruded material has a misorientation angle distribution which is close to the theoretical random distribution and with $~ 95 \%$ HAGBs. 
Furthermore, there is no significant decrease in the fraction of HAGBs when the HPT processing is conducted through different numbers of turns.

\subsection{Texture evolution during HPT processing}

A series of EBSD orientation images are presented in Fig. 5 including (a) the as-received condition and after HPT through (b) 1/2, (c) 1 and (d) 5 turns where the images after HPT were recorded at the mid-radius positions of the disks. In Fig. 5 the grain orientations are depicted by different colors which are shown in the unit triangle below the images and the LAGBs and HAGBs are denoted using yellow and black lines in the EBSD micrographs, respectively. It can be seen that the grain size and texture both change with straining of the material.

The corresponding inverse pole figures of the EBSD orientation maps are shown in Fig. 6 and it is apparent that the basal planes are typically aligned perpendicular to ND which corresponds to the torsional axis. This is shown by the high intensities around $\{10 \overline{1} 0\}$ and $\{2 \overline{1} \overline{1} 0\}$ parallel to ND. High intensities also continue to be observed along $\{10 \overline{1} 0\}$ and $\{2 \overline{1} \overline{1} 0\}$ at ND after processing by $1 / 2$ and 1 turns of HPT and this corresponds to the $c$-axis perpendicular to ND. However, it should be noted that the maximum intensities observed in the inverse pole figures decrease after $1 / 2$ turn and they decrease even more after 1 turn which shows that there is a gradual dissolution of the initial strong texture. After processing by 5 turns of HPT, the inverse pole figure shows clearly a change in texture and the majority of basal $\{0001\}$ planes are then oriented parallel to ND.

\subsection{The evolution in microhardness}

When processing by HPT, the imposed torsional strain varies across the disk and the equivalent von Mises strain, $\varepsilon_{\mathrm{eq}}$ is given by a relationship of the form $[42,43]$ : 


$$
\varepsilon_{e q}=\frac{2 \pi N r}{h \sqrt{3}}
$$

where $N$ is the number of revolutions in HPT processing, $r$ is the radius and $h$ is thickness of the disk. It follows from Eq. (1) that $\varepsilon_{\mathrm{eq}}$ is a maximum at the edge of the disk and decreases to zero at the center of the disk where $r=0$.

It was shown in early studies that hardness measurements in HPT disks are most readily correlated by plotting the hardness values against the equivalent strain on linear axes [45] and Fig. 7 shows this plot using microhardness values recorded on cross-sectional planes along randomly selected diameters. The datum points in Fig. 7 relate to HPT processing through 1/8, $1 / 4,1 / 2,1,2$ and 5 turns under a pressure of $2.0 \mathrm{GPa}$ and it is apparent that all points are in reasonable agreement and fall around the solid line. The lower dashed line denotes the hardness value in the as-received condition. Thus, in the early stages of HPT the hardness values rise quickly with the accumulating strain but there is no significant further increase at equivalent strains above $\sim 20$ and ultimately the microhardness values become essentially saturated at $\mathrm{Hv}$ $\approx 125$ at high strains. This evolution is consistent with a theoretical evaluation based on strain gradient plasticity modeling [44].

\section{Discussion}

\subsection{Microstructures during processing by HPT}

It is now well established that the SPD processing of fcc metals leads to a condition in which the large grains become subdivided by low-angle boundaries and these subgrain boundaries progressively evolve into high-angle boundaries through further straining of the sample [46]. This mechanism of structural refinement is characterized by large fractions of lowangle boundaries that are present in the very early stages of deformation but with a subsequent 
increase in the fraction of high-angle boundaries at larger strains [17]. However, the refinement process for hcp metals is not the same as in fcc metals because initially a bimodal grain structure develops due to the formation of a necklace-like microstructure as a result of dynamic recrystallization $[19,32,47]$. In this process, new finer grains are formed along the grain boundaries of the initial coarser structure giving a duality in structure, and these finer grains gradually consume the larger grains with increasing straining and thereby produce an ultrafine structure. In this mechanism, it is expected that the distributions of the misorientation angles will not change significantly during processing. The present results shown in Fig. 4 are in agreement with these predictions and the measurements recorded in Table 2 confirm there is no change in the area fractions of LAGBs during the HPT process.

In order to study the distribution formation of the ultrafine grains $(<1 \mu \mathrm{m})$ within the microstructure during processing, Fig. 8 provides corresponding analyses of the image quality (IQ) maps based on Fig. 2 for the samples processed through 1/2, 1 and 5 turns. Using an OIM analyzer, Fig. 8(a)-(c) are divided into two distinct fractions of either ultrafine grains (grey color) or grains having sizes larger than $1 \mu \mathrm{m}$ (white color). By comparison to the maps between different stages of straining, it is apparent that new ultrafine grains (UFG) are created in the form of aggregates along the grain boundaries of the large grains and these areas occupy $\sim 15 \%$ and $\sim 25 \%$ of the microstructure after $1 / 2$ and 1 turn of HPT to give an island-like structure in Figs 8(a) and (b). Continual straining up to 5 turns expands these UFG aggregates until they cover $\sim 75 \%$ of the total area although some coarser grains remain in the microstructure and this leads to a spread in the grain size distribution as shown in Fig. 3. These observations are consistent with the conventional model describing the formation of shear zones in magnesium from the bands of recrystallized grains [48]. It was proposed in the model that very small recrystallized 
grains form along the original grain boundaries when satisfactorily oriented for basal slip but shear cannot easily occur due to the constraints imposed by the adjacent larger grains. However, by applying a large strain the recrystallized bands broaden and provide a pathway for easy slip through the specimen. Thus, it is anticipated that high local stresses in advance of these bands will promote local strain and successive recrystallization, and when a clear path for shear deformation is formed through the specimen the deformation will become more concentrated and will produce a shear zone.

The evolution of the grain size distribution shown in Fig. 3, together with the quantitative analyses of grains sizes and area fractions summarized in Table 1, confirm that there is a gradual refinement through HPT processing at room temperature such that the distributions of grain sizes move sequentially from a peak at $\sim 2 \mu \mathrm{m}$ after $1 / 2$ turn to a peak at $\sim 1 \mu \mathrm{m}$ after 5 revolutions of HPT and the consequent formation of a UFG structure with grains having sizes of $<1 \mu \mathrm{m}$. Nevertheless, it is noted from close inspection of Fig. 3 that the distribution after 5 turns also exhibits another distinct peak at a grains size of $<0.5 \mu \mathrm{m}$. This second peak leads to an area fraction of $\sim 35 \%$ of grains having sizes $<0.5 \mu \mathrm{m}$ as shown in Table 1 .

Figure 9 provides a direct illustration of the evolution in the misorientation angles from the extruded condition through to 5 turns of HPT processing with all measurement taken at the mid-radius positions. It is apparent from Fig. 9 that $\sim 14 \%$ of the boundaries within the larger grains contain misorientation angles of $\sim 90^{\circ}$ in the early stages of HPT by straining the sample for $1 / 2$ revolution. It is known that a lattice misorientation angle of $86.2^{\circ}$ is caused by $\{10 \overline{1} 2\}$ twinning [49]. An EBSD analysis of a magnesium single crystal during unidirectional compressive deformation at RT showed that the early stage of deformation in the single crystal was characterized by profuse $\{10 \overline{1} 2\}$ twining [50] and this can convert the whole sample into 
relatively softer orientations for slip and thereby eliminate the initial unfavorable orientation of the single crystal. Observations of microstructural evolution of ZK60 processed by HPT showed that twins existed more abundantly in the coarser grains located at the center and half-radius positions in the early stages of HPT [23,24]. Successive secondary and tertiary $\{10 \overline{1} 2\}$ twins were also found to form in the primary twinned areas. Therefore, the observed peak in the range of $85-90^{\circ}$ in early stages of HPT is attributed to the misorientation angles that lie between the original grain and the twin bands.

Another peak with a value of $\sim 14 \%$ of the misorientation angles was present at an angle of $\sim 30^{\circ}$ in the final stages of HPT after 5 turns as shown in Fig. 4(d). An investigation of ductility in single crystal magnesium from a specimen strained to -1.0 showed that a very high frequency peak gradually appeared at about $30^{\circ} \pm 5^{\circ}$ in the misorientation angle distribution [50] and similar peaks at $30^{\circ}$ were also reported in earlier investigation using a rolled AZ31 alloy [38] and in commercial purity Mg processed by HPT for 10 turns and then annealed at $373 \mathrm{~K}$ for $24 \mathrm{~h}$ [52]. Comprehensive textural observations confirmed that the newly recrystallized grains formed within the twin bands rotated in parallel around the $c$-axis of the original twin by an average of about $30^{\circ}$ and their formation is attributed to the successive fragmentation of the twin bands due to prismatic slip and further continuous dynamic recrystallization [50,51]. It should be noted that a peak in the misorientation distribution is also expected in magnesium with a basal fiber texture [37-39] and the present results suggest the formation of this texture after 5 turns of HPT.

\subsection{Microhardness evolution:}


The Hollomon equation is generally used to correlate the true stress and true strain data with the strength coefficient and the strain-hardening exponent using the following relationship [53]:

$$
\sigma=K \varepsilon_{p}^{n}
$$

where $\sigma$ is the true stress, $K$ is a material constant, $\varepsilon_{\mathrm{p}}$ is the true strain and $n$ is the strain hardening index. In practice, this equation can be simplified for hardness values in order to evaluate the strain hardening behavior occurring in the early stages of HPT. Thus, very early work showed that for steels having a wide range of carbon contents there was a linear relationship of the form [54]

$$
\sigma=c H
$$

where $c$ is related to the material. Furthermore, it was subsequently shown that metals exhibiting little strain hardening have $c \approx 0.36$ [55].

A quantitative analysis was conducted to estimate the extent of strain hardening using the Hv measurements. In this method, by replacing $\sigma$ with $\mathrm{Hv}$ from Eq. (3) and $\varepsilon_{\mathrm{p}}$ with $\varepsilon_{\mathrm{eq}}$ from Eq. (1), a modified form of Eq. (3) may be rewritten as

$$
H v=K^{\prime} \varepsilon_{e q}^{\eta}
$$

where $K^{\prime}$ is a new materials constant and $\eta$ is the hardenability exponent which corresponds to the slope in a double logarithmic plot of the Hv values against the equivalent strain in HPT.

Figure 10 shows a double logarithmic plot of the $\mathrm{Hv}$ values against $\varepsilon_{\text {eq }}$ for the ZK60 alloy after up to 5 turns of HPT using data extracted from Fig. 7. It can be seen that the datum points up to $\varepsilon_{e q} \leq 20$ are well fitted by a straight inclined line before the saturation condition at the highest strains and the slope of this inclined line gives the hardenability exponent which is $\eta \approx$ 0.07. The upper dashed line in Fig. 10 corresponds to the saturated value of the microhardness at 
high equivalent strains. Thus, the hardenability exponent is in a good agreement with other exponents reported for magnesium alloys processed by HPT [26,56].

Table 3 summarizes the available strain hardening data for materials processed by HPT. These data are useful for developing a phenomenological model to estimate the minimum level of accumulated strain or the numbers of HPT turns required to obtain a level of saturated hardness for different materials. By replacing $\varepsilon_{\text {eq }}$ from Eq. (1) in the hardenability of Eq. (4), it follows that

$$
N_{P, T}=\frac{h \sqrt{3}}{2 \pi r}\left(\frac{H_{s a t}}{K^{\prime}}\right)^{-\eta}
$$

where $N_{\mathrm{P}, \mathrm{T}}$ is the estimated minimum number of HPT turns in order to achieve a saturation hardness at a distance $r$ from the center of the disk.

Based on a comparison of the different metals processed by HPT processing and summarized in Table 3, different strain hardening behaviors may be identified during HPT. In each hardness evolution, the degree of the strain hardening or strain softening may be conveniently expressed by the hardenability exponent, $\eta$. When $\eta>0$, it is apparent that the hardness increases initially with increasing equivalent strain and then saturates at a maximum hardness at reasonably high strains. In Table 3 the high purity (HP) aluminum exhibits a similar strain hardening with $\eta>0$ but there is a subsequent softening with $\eta<0$ in which there is microstructural recovery and a saturation hardness is achieved after reasonably large numbers of HPT turns [57]. For metals such as the $\mathrm{Zn}-22 \% \mathrm{Al}$ eutectoid alloy, the hardenability is $\eta<0$ $[58,59,62]$ and the strain softening and decrease in hardness is followed by an ultimate saturation with increasing equivalent strain. As noted in a comprehensive review [56], this hardness behavior is essentially the opposite of the conventional strain hardening behavior obtained in the 
present investigation and the weakening in the two-phase alloy is due to the decomposition of hard $\mathrm{Zn}$ precipitates as a result of changes in the precipitation kinetics in the Al-rich phase due to the application of SPD through the HPT processing [63] and to the transformation of a lamellar structure into an ultrafine-grained equiaxed structure [60].

\section{Summary and conclusions}

1. A ZK60 magnesium alloy was processed by HPT at ambient temperature under a pressure of $2.0 \mathrm{GPa}$ for up to 5 turns to produce an average grain size of $\sim 700 \mathrm{~nm}$ and a reasonable homogeneity.

2. Using EBSD analysis it is shown that there is an evolution in the grain orientations from an extruded texture with prismatic $\{10 \overline{1} 0\}$ planes lying parallel to the surfaces of the disks to an ultimate basal $\{0001\}$ fiber texture with the $c$-axis parallel to ND after 5 turns of HPT.

3. The misorientation angle evolution during HPT processing shows peaks in the range of $85-90^{\circ}$ and these are due to the contribution of tensile twinning. A peak detected in the ultrafinegrained structure at $\sim 30^{\circ}$ is attributed to the basal fiber texture.

4. The ZK60 alloy shows an evolution towards a hardness homogeneity after 5 turns of HPT with a hardenability exponent of $\eta \approx 0.07$ measured for equivalent strains up to $\sim 20$ and a subsequent saturation hardness at $\mathrm{Hv} \approx 125$.

\section{Acknowledgement}

This work was supported by the National Science Foundation of the United States under Grant No. DMR-1160966. 


\section{References:}

1. F.H. Froes, D. Eliezer, E. Aghion, The science, technology, and applications of magnesium, JOM 50(9) (1998) 30-34.

2. K. Johnson, Magnesium automotive applications, Adv. Mater. Proc., 160(6) (2002) 62-65.

3. M.P. Staiger, A.M. Pietak, J. Huadmai, G. Dias, Magnesium and its alloys as orthopedic biomaterials: A review, Biomater. 27 (2006) 1728-1734.

4. K. Kubota, M. Mabuchi, K. Higashi, Review: Processing and mechanical properties of finegrained magnesium alloys, J. Mater. Sci. 34 (1999) 2255-2262.

5. T. Mukai, H. Watanabe, K. Higashi, Application of superplasticity in commercial magnesium alloy for fabrication of structural components, Mater. Sci. Tech. 16 (2000) 13141319.

6. H. Watanabe, T. Mukai, M. Mabuchi, K. Higashi, Superplastic deformation mechanism in powder metallurgy magnesium alloys and composites, Acta Mater. 49 (2001) 2027-2037.

7. R.Z. Valiev, Y. Estrin, Z. Horita, T.G. Langdon, M.J. Zehetbauer, Y.T. Zhu, Producing bulk ultrafine-grained materials by severe plastic deformation, JOM 58(4) (2006) 33-39.

8. T.G. Langdon, Twenty-five years of ultrafine-grained materials: achieving exceptional properties through grain refinement, Acta Mater. 61 (2013) 7035-7059.

9. R.Z. Valiev, Y. Estrin, Z. Horita, T.G. Langdon, M.J. Zehetbauer, Y.T. Zhu, Producing bulk ultrafine-grained materials by severe plastic deformation: ten years later, JOM 68 (2016) 1216-1226.

10. R.Z. Valiev, T.G. Langdon, Principles of equal-channel angular pressing as a processing tool for grain refinement, Prog. Mater. Sci. 51 (2006) 881-981. 
11. A.P. Zhilyaev, T.G. Langdon, Using high-pressure torsion for metal processing: Fundamentals and applications, Prog. Mater. Sci. 53 (2008) 893-979.

12. A.P. Zhilyaev, B.K. Kim, G.V. Nurislamova, M.D. Baró, J.A. Szpunar, T.G. Langdon, Orientation imaging microscopy of ultrafine-grained nickel, Scr. Mater. 46 (2002) 575-580.

13. A.P. Zhilyaev, G.V. Nurislamova, B.K. Kim, M.D. Baró, J.A. Szpunar, T.G. Langdon, Experimental parameters influencing grain refinement and microstructural evolution during high-pressure torsion, Acta Mater. 51 (2003) 753-765.

14. J. Wongsa-Ngam, M. Kawasaki, T.G. Langdon, A comparison of microstructures and mechanical properties in a $\mathrm{Cu}-\mathrm{Zr}$ alloy processed using different SPD techniques, J. Mater. Sci. 48 (2013) 4653-4660.

15. S. Sabbaghianrad, M. Kawasaki, T.G. Langdon, Microstructural evolution and the mechanical properties of an aluminum alloy processed by high-pressure torsion, J Mater. Sci. 47 (2012) 7789-7795.

16. S. Sabbaghianrad, J. Wongsa-Ngam, M. Kawasaki, T.G Langdon, An examination of the saturation microstructures achieved in ultrafine-grained metals processed by high-pressure torsion, J. Mater. Res. Technol. 3 (2014) 319-326.

17. S. Sabbaghianrad, T.G. Langdon, An evaluation of the saturation hardness in an ultrafinegrained aluminum 7075 alloy processed using different techniques, J. Mater. Sci. 30 (2015) 4357-4365.

18. B.J. Bonarski, E. Schafler, B. Mingler, W. Skrotzki, B. Mikulowski, M. J. Zehetbauer, Texture evolution of Mg during high-pressure torsion, J. Mater. Sci. 43 (2008) 7513-7518.

19. R.B. Figueiredo, T.G. Langdon, Principles of grain refinement in magnesium alloys processed by equal-channel angular pressing, J. Mater. Sci. 44 (2009) 4758-4762. 
20. Y. Huang, R.B. Figueiredo, T. Baudin, A.L. Helbert, F. Brisset, TG. Langdon, Microstructure and texture evolution in a magnesium alloy during processing by highpressure torsion, Mater. Res. 16 (2013) 577-585.

21. Y.C. Wang, T.G. Langdon, Effect of heat treatment on microstructure and microhardness evolution in a Ti-6Al-4V alloy processed by high-pressure torsion, J. Mater .Sci. 48 (2013) 4646-4652.

22. L. Wang, Y.C. Wang, A.P. Zhilyaev, A.V. Korznikov, S.K. Li, E. Korznikova, T.G. Langdon, Microstructure and texture evolution in ultrafine-grained pure Ti processed by equal-channel angular pressing with subsequent dynamic compression, Scr. Mater. 77 (2014) 33-36.

23. S.A. Torbati-Sarraf, S. Sabbaghianrad, T.G. Langdon, Microstructural properties, thermal stability and superplasticity of a ZK60 Mg alloy processed by high-pressure torsion, Letters Mater. 5 (2014) 287-293.

24. S.A. Torbati-Sarraf, T.G. Langdon, Mechanical properties of ZK60 magnesium alloy processed by high-pressure torsion, Adv. Mater. Res. 922 (2014) 767-772.

25. S.A. Torbati-Sarraf, T.G. Langdon, Properties of a ZK60 magnesium alloy processed by high-pressure torsion, J. Alloy Compd. 613 (2014) 357-363.

26. H.J. Lee, S.K. Lee, K.H. Jung, G.A. Lee, B. Ahn, M. Kawasaki, T.G. Langdon, Evolution in hardness and texture of a ZK60A magnesium alloy processed by high-pressure torsion, Mater. Sci. Eng. A630 (2015) 90-98.

27. I.C. Choi, D.H. Lee, B. Ahn, K. Durst, M. Kawasaki, T.G. Langdon, J.I. Jang, Enhancement of strain-rate sensitivity and shear yield strength of a magnesium alloy processed by highpressure torsion, Scr. Mater. 94 (2015) 44-47. 
28. R.B. Figueiredo, P.R. Cetlin, T.G. Langdon, Using finite element modeling to examine the flow processes in quasi-constrained high-pressure torsion, Mater. Sci. Eng. A528 (2011) 8198-8204.

29. R.B. Figueiredo, P.H.R. Pereira, M.T.P. Aguilar, P.R. Cetlin, T.G. Langdon, Using finite element modeling to examine the temperature distribution in quasi-constrained highpressure torsion, Acta Mater. 60 (2012) 3190-3198.

30. K. Edalati, Z. Horita, T.G. Langdon, The significance of slippage in processing by highpressure torsion, Scr. Mater. 60 (2009) 9-12.

31. M. Kawasaki, T.G. Langdon, The significance of strain reversals during processing by highpressure torsion, Mater. Sci. Eng. A498 (2008) 341-348.

32. R.B. Figueiredo, T.G. Langdon, The nature of grain refinement in equal-channel angular pressing: a comparison of representative fcc and hcp metals, Int. J. Mater. Res. 100 (2009) 1638-1646.

33. Y. Huang, R.B. Figueiredo, T. Baudin, F. Brisset, T.G. Langdon, Evolution of strength and homogeneity in a magnesium AZ31 alloy processed by high-pressure torsion at different temperatures, Adv. Eng. Mater. 14 (2012) 1018-1026.

34. Y. Huang, R.B Figueiredo, T. Baudin, A.L Helbert, F. Brisset, T.G. Langdon, Effect of temperature on the processing of a magnesium alloy by high-pressure torsion, J. Mater. Sci. 47 (2012) 7796-7806.

35. L.S. Tóth, B. Beausir, C.F. Gu, Y. Estrin, N. Scheerbaum, C.H.J Davies, Effect of grain refinement by severe plastic deformation on the next-neighbor misorientation distribution, Acta Mater. 58 (2010) 6706-6716. 
36. L.S. Tóth, C. Gu, Ultrafine-grain metals by severe plastic deformation, Mater. Charact. 92 (2014) $1-14$.

37. J.A. del Valle, M.T. Pérez-Prado, O.A. Ruano, The distribution of disorientation angles in a rolled AZ31 Mg alloy, Rev. Metal. Madrid 38 (2002) 353-357.

38. J.A. del Valle, M.T. Pérez-Prado, O.A. Ruano, Deformation mechanisms responsible for the high ductility in a Mg AZ31 alloy analyzed by electron backscattered diffraction, Metall. Mater. Trans. A 36A (2005) 1428-1437.

39. J.A. del Valle, O.A. Ruano, Separate contributions of texture and grain size on the creep mechanisms in a fine-grained magnesium alloy, Acta Mater. 55 (2007) 455-466.

40. J.K. Mackenzie, M.J. Thomson, Some statistics associated with the random disorientation of cubes, Biometrika 44 (1957) 205-210.

41. J.K. Mackenzie, Second paper on statistics associated with the random disorientation of cubes, Biometrika 45 (1958) 229-240.

42. R.Z. Valiev, Yu.V. Ivanisenko, E.F Rauch,B. Baudelet, Structure and deformation behavior of Armco iron subjected to severe plastic deformation, Acta Mater. 44 (1996) 4705-4712.

43. F. Wetscher, A. Vorhauer, R. Stock, R. Pippan, Structural refinement of low alloyed steels during severe plastic deformation, Mater. Sci. Eng. A387-389 (2004) 809-816.

44. Y. Estrin, A. Molotnikov, C.H.J. Davies, R. Lapovok, Strain gradient modeling of highpressure torsion, J. Mech. Phys. Solids 56 (2008) 1186-1202.

45. A. Vorhauer, R. Pippan, On the homogeneity of deformation by high pressure torsion, Scr. Mater. 51 (2004) 921-925.

46. T.G. Langdon, The principles of grain refinement in equal-channel angular pressing, Mater. Sci. Eng. A462 (2007) 3-11. 
47. R.B. Figueiredo, T.G. Langdon, Grain refinement and mechanical behaviour of a magnesium alloy processed by ECAP, J. Mater. Sci. 45 (2010) 4827-4836.

48. S.E. Ion, F.J. Humphreys, S.H. White, Dynamic recrystallisation and the development of microstructure during the high temperature deformation of magnesium, Acta Metall. 30 (1982) 1909-1919.

49. P.G. Partridge, The crystallography and deformation modes of hexagonal close-packed metals, Metall. Rev. 12 (1967) 169-194.

50. K.D. Molodov, T. Al-Samman, D.A. Molodov, G. Gottstein, Mechanisms of exceptional ductility of magnesium single crystal during deformation at room temperature: Multiple twinning and dynamic recrystallization, Acta Mater. 76 (2014) 314-330.

51. K.D. Molodov, T. Al-Samman, D.A. Molodov, G. Gottstein, On the ductility of magnesium single crystals at ambient temperature, Metall. Mater. Trans. A 45A (2014) 3275-3281.

52. R.B. Figueiredo, S. Sabbaghianrad, A. Giwa, J.R. Greer, T.G. Langdon, Evidence for exceptional low temperature ductility in polycrystalline magnesium processed by severe plastic deformation, Acta Mater. 122 (2017) 322-331.

53. J.H. Hollomon, Tensile deformation, Trans. Am. Inst. Min. Metall. Pet. Eng. 162 (1945) 268-290.

54. J.A. Brinell, Brinell's method of determining hardness and other properties of iron and steel, J. Iron. Steel Inst. 59 (1901) 243-298

55. H. O'Neill, The Hardness of Metals and its Measurement, Chapman and Hall, London, England (1934).

56. M. Kawasaki, Different models of hardness evolution in ultrafine-grained materials processed by high-pressure torsion, J. Mater. Sci. 49 (2014) 18-34. 
57. M. Kawasaki, R.B. Figueiredo, T.G. Langdon, An investigation of hardness homogeneity throughout disks processed by high-pressure torsion, Acta Mater. 59 (2011) 308-316.

58. M. Kawasaki, B. Ahn, T.G. Langdon, Microstructural evolution in a two-phase alloy processed by high-pressure torsion, Acta Mater. 58 (2010) 919-930.

59. N.X. Zhang, M. Kawasaki, Y. Huang, T.G. Langdon, Microstructural evolution in twophase alloys processed by high-pressure torsion, J. Mater. Sci. 48 (2013) 4582-91.

60. T.S. Cho, H.J. Lee, B. Ahn, M. Kawasaki, T.G. Langdon, Microstructural evolution and mechanical properties in a $\mathrm{Zn}-\mathrm{Al}$ eutectoid alloy processed by high-pressure torsion. Acta Mater. 72 (2014) 67-79.

61. M. Kawasaki, R.B. Figueiredo, Y. Huang, T.G. Langdon, Interpretation of hardness evolution in metals processed by high-pressure torsion, J. Mater. Sci. 49 (2014) 6586-6596.

62. M. Kawasaki, B. Ahn, T.G. Langdon, Significance of strain reversals in a two-phase alloy processed by high-pressure torsion, Mater. Sci. Eng. A527 (2010) 7008-7016.

63. M. Furukawa, Z. Horita, M. Nemoto, R.Z. Valiev, T.G. Langdon, Fabrication of submicrometer-grained Zn-22\% Al by torsion straining. J. Mater. Res. 11 (1996) 2128-30. 


\section{Figure Captions:}

Figure 1. Near-surface position of the disks for EBSD sample preparation with ion beam crosssectional polishing facility: ND, TD and RD correspond to Normal Direction (torsion axis), Tangential Direction and Radial Direction, respectively, and the inset shows the shear direction is parallel to TD.

Figure 2. Image quality (IQ) maps of ZK60 (a) as-received and after (b) 1/2 turn, (c) 1 turn and (d) 5 turns of HPT in the mid-radius positions of the disks.

Figure 3. Grain size distributions of ZK60 in the as-received condition and after 1/2, 1 and 5 turns of HPT in the mid-radius positions of the disks.

Figure 4. Number fractions of the misorientation angles of ZK60 in (a) the as-received extruded condition and after (b) 1/2 turn, (c) 1 turn and (d) 5 turns of HPT in the mid-radius positions of the disks.

Figure 5. EBSD orientation micrographs of ZK60 in (a) the as-received condition and after (b) 1/2 turn, (c) 1 turn and (d) 5 turns of HPT in the mid-radius positions of the disks.

Figure 6. The inverse pole figures of $\{0001\},\{101 \overline{0}\}$ and $\{21 \overline{1} \overline{0}\}$ crystallographic orientations with respect to TD, RD and ND of the HPT directions from the mid-radius positions of the extruded disk and processed disks with $\mathrm{N}=1 / 2,1$ and 5 turns of HPT at $298 \mathrm{~K}$.

Figure 7. Variation of the microhardness values with equivalent strain for ZK60 after processing by $1 / 8,1 / 4,1 / 2,1,2$ and 5 turns of HPT under an applied pressure of $2.0 \mathrm{GPa}$ : the lower dashed line represents the microhardness value of the as-received extruded material.

Figure 8. Distribution maps of ultrafine grains $(<1 \mu \mathrm{m})$ during straining of samples through (a) 1/2, (b) 1 and (c) 5 turns of HPT. 
Figure 9. Comparison of number fractions of misorientation angles in ZK60 alloy for the extruded condition and after processing by HPT for 1/2, 1 , and 5 turns of HPT in the mid-radius positions of the disks.

Figure 10. Plot of the Hv values against $\varepsilon_{\mathrm{eq}}$ in a double-logarithmic scale for the ZK60 alloy after up to 5 turns of HPT under $2.0 \mathrm{GPa}$ at ambient temperature: the inclined solid line denotes the hardenability exponent of $\eta \approx 0.07$ and the dashed line denotes the saturation hardness at $\varepsilon_{\text {eq }}$ $>20$.

\section{Table Captions:}

Table 1. Average grain size and area fraction percentiles of grains smaller than 1.0 and $0.5 \mu \mathrm{m}$ in the extruded condition and after HPT through 1/2, 1 and 5 turns.

Table 2. The fraction percentiles of HAGBs, LAGBs, $30^{\circ}$ and $85^{\circ}-90^{\circ}$ misorientation angles in the extruded condition and after HPT through 1/2, 1 and 5 turns.

Table 3. Summary of the saturation levels and hardenability of HPT processed materials where 298/ $T_{m}$ denotes the homologous temperatures for HPT processing at room temperature. 
Table 1.

\begin{tabular}{lccc}
\hline HPT turns & Grain size $(\mu \mathrm{m})$ & \multicolumn{2}{c}{ Area fraction percentile $(\%)$} \\
\cline { 3 - 4 } & & $<1.0(\mu \mathrm{m})$ & $<0.5(\mu \mathrm{m})$ \\
\hline Extruded & $5.0 \pm 2.5$ & 0 & 0 \\
$1 / 2$ & $1.9 \pm 1.2$ & 15 & 3 \\
1 & $1.7 \pm 0.9$ & 25 & 3 \\
5 & $0.7 \pm 0.5$ & 75 & 35 \\
\hline
\end{tabular}


Table 2.

\begin{tabular}{|c|c|c|c|c|}
\hline \multirow{2}{*}{ HPT turns } & \multicolumn{4}{|c|}{ Fraction of misorientation angles percentile (\%) } \\
\hline & HAGBs & LAGBs & $30^{\circ}$ & $85-90^{\circ}$ \\
\hline Extruded & 95 & 5 & 7 & 8 \\
\hline $1 / 2$ & 95 & 5 & 8 & 14 \\
\hline 1 & 95 & 5 & 7 & 12 \\
\hline 5 & 96 & 4 & 14 & 11 \\
\hline
\end{tabular}


Table 3.

\begin{tabular}{|c|c|c|c|c|c|c|c|c|c|c|c|}
\hline \multirow[t]{2}{*}{ Material } & \multirow[t]{2}{*}{ Initial Condition } & \multicolumn{3}{|c|}{ Processing conditions } & \multicolumn{2}{|c|}{$\begin{array}{l}\text { Average. grain } \\
\text { size } \\
(\mu \mathrm{m})\end{array}$} & \multicolumn{2}{|c|}{$\mathrm{Hv}\left(\mathrm{kgf} / \mathrm{mm}^{2}\right)$} & \multicolumn{2}{|c|}{ Hardenability } & \multirow[t]{2}{*}{ Reference } \\
\hline & & $298 / T_{\mathrm{m}}$ & $\overline{\varepsilon_{\mathrm{eq}}}$ & $\begin{array}{c}\mathrm{P} \\
(\mathrm{GPa})\end{array}$ & $\mathrm{d}_{\mathrm{i}}$ & $\mathrm{d}_{\mathrm{f}}$ & Initial & Saturation & $K^{\prime}\left(\mathrm{kgf} / \mathrm{mm}^{2}\right)$ & $\bar{\eta}$ & \\
\hline $\begin{array}{l}\text { Ti-6Al- } \\
4 \mathrm{~V}\end{array}$ & $1 \mathrm{~h}$ at $1023 \mathrm{~K}$ & 0.15 & 30 & 6.0 & 10.1 & 130 & 295 & 365 & 31 & 0.031 & {$[21]$} \\
\hline $\begin{array}{l}\text { Ti-6Al- } \\
4 \mathrm{~V}\end{array}$ & $\begin{array}{l}1 \mathrm{~h} \text { at } 1223 \mathrm{~K}+4 \mathrm{~h} \text { at } \\
873 \mathrm{~K}\end{array}$ & 0.15 & 30 & 6.0 & 9.7 & 70 & 305 & 405 & 32 & 0.052 & [21] \\
\hline HP Al & $1 \mathrm{~h}$ at $773 \mathrm{~K}$ & 0.32 & $0-3$ & 6.0 & 1000 & 1.4 & 20 & 43 & 42 & 0.18 & {$[57]$} \\
\hline HP Al & $1 \mathrm{~h}$ at $773 \mathrm{~K}$ & 0.32 & $3-10$ & 6.0 & - & 1.4 & 43 & 37 & 63 & -0.24 & [57] \\
\hline $\mathrm{Zn}-22 \mathrm{Al}$ & $1 \mathrm{~h}$ at $753 \mathrm{~K}$ & $0.51 *$ & 40 & 3.0 & 1.4 & 0.35 & 68 & 24 & 61 & -0.22 & {$[58-60]$} \\
\hline ZK60 & Extruded & 0.32 & 20 & 6.0 & 10 & - & 72 & 110 & 84 & 0.07 & {$[25]$} \\
\hline AZ31 & Extruded & 0.32 & 30 & 6.0 & 10 & 0.9 & 60 & 115 & 83 & 0.08 & [61] \\
\hline ZK60 & Extruded & 0.32 & 20 & 2.0 & 10 & 0.7 & 74 & 120 & 99 & 0.07 & $\begin{array}{c}\text { This } \\
\text { investigation }\end{array}$ \\
\hline
\end{tabular}

* With respect to eutectoid alloy 


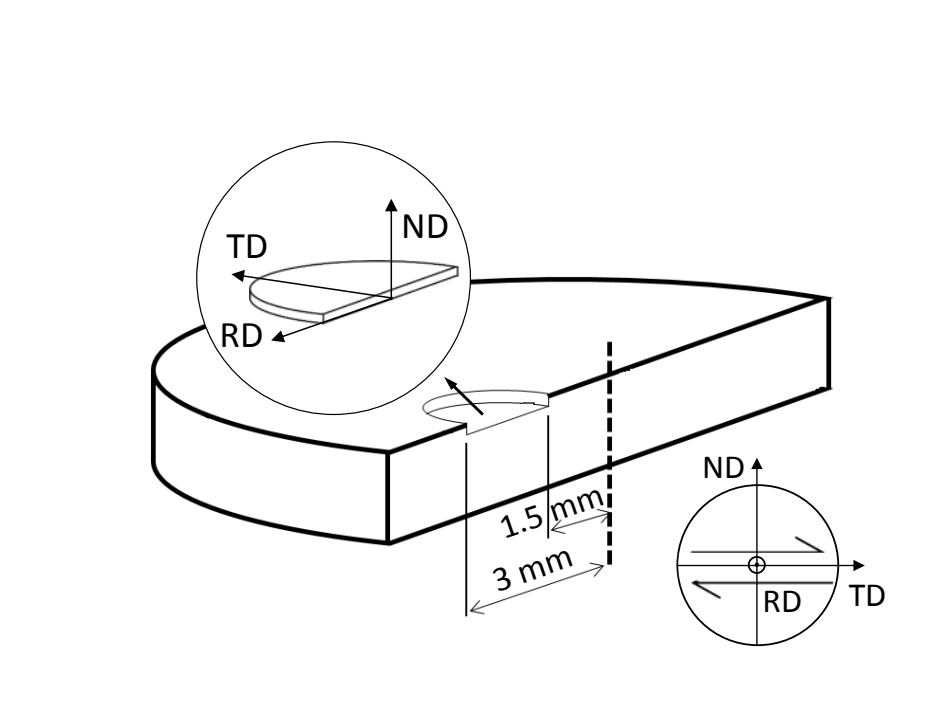

Fig. 1

Figure

Fig. 1

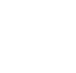

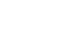

$+2$

Fig 

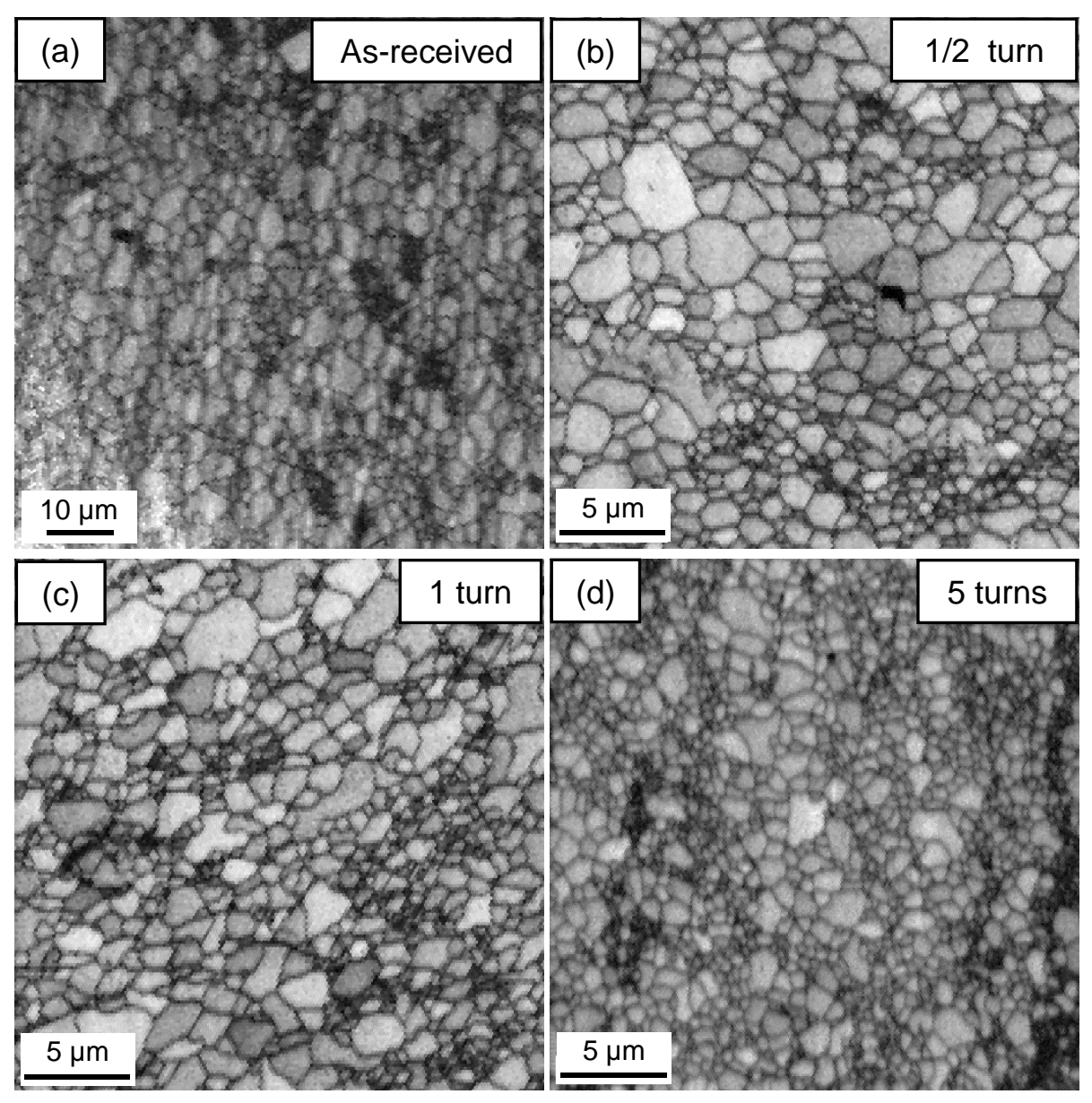

Fig. 2

$5 \mu \mathrm{m}$

2

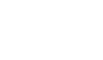




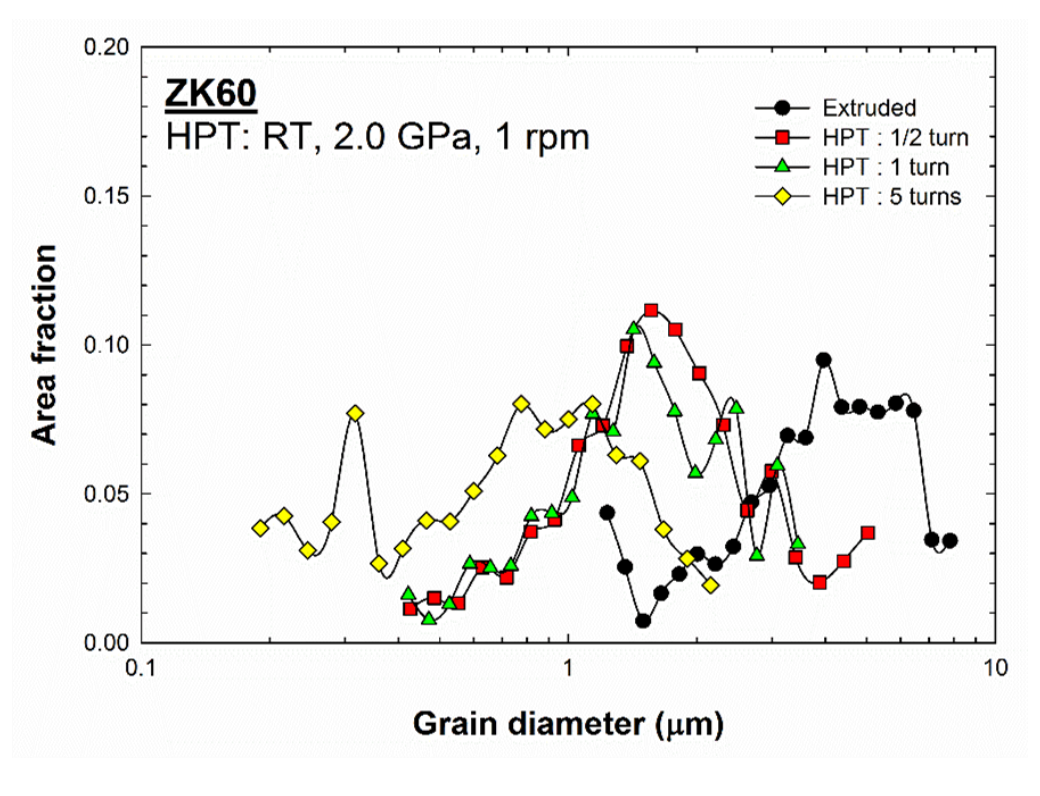

Fig. 3

Figure

Grain diameter $(\mu \mathrm{m})$

Fig. 3
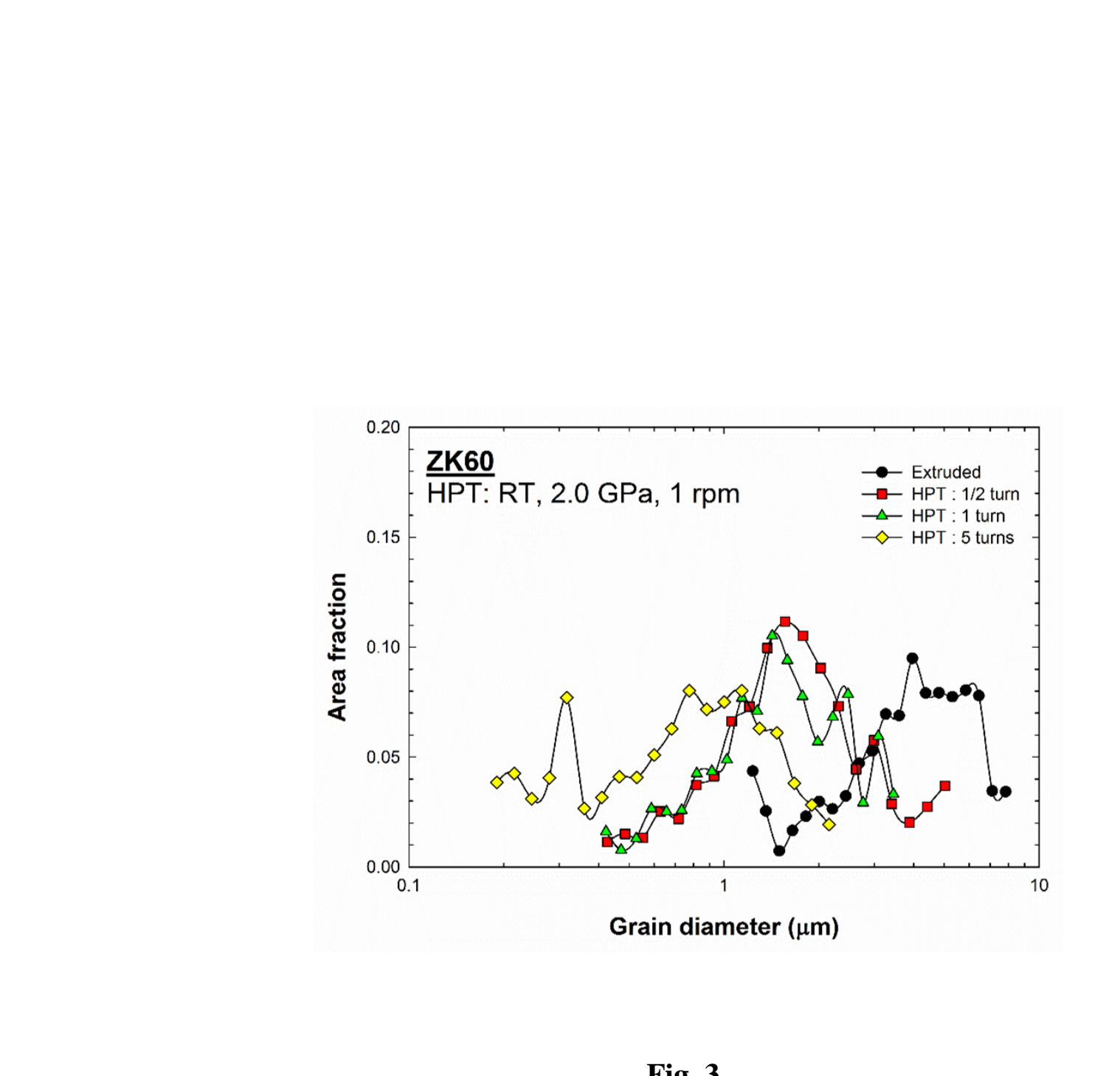

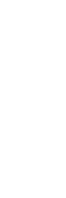
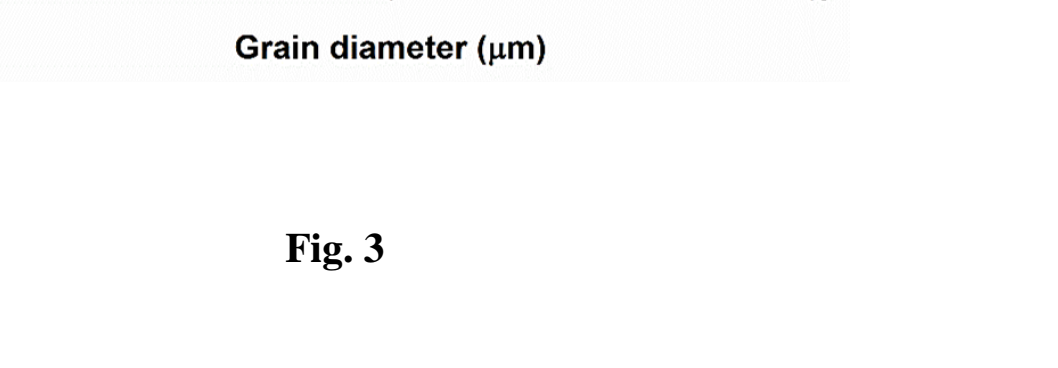


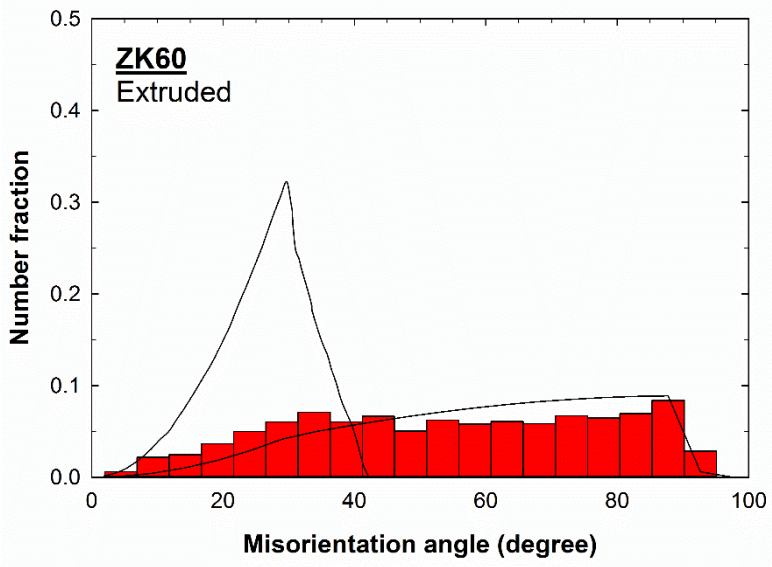

(a)

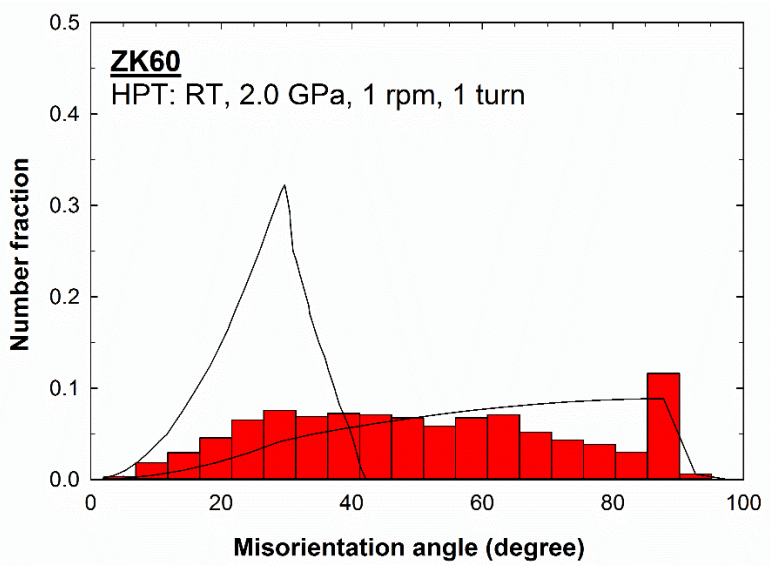

(c)

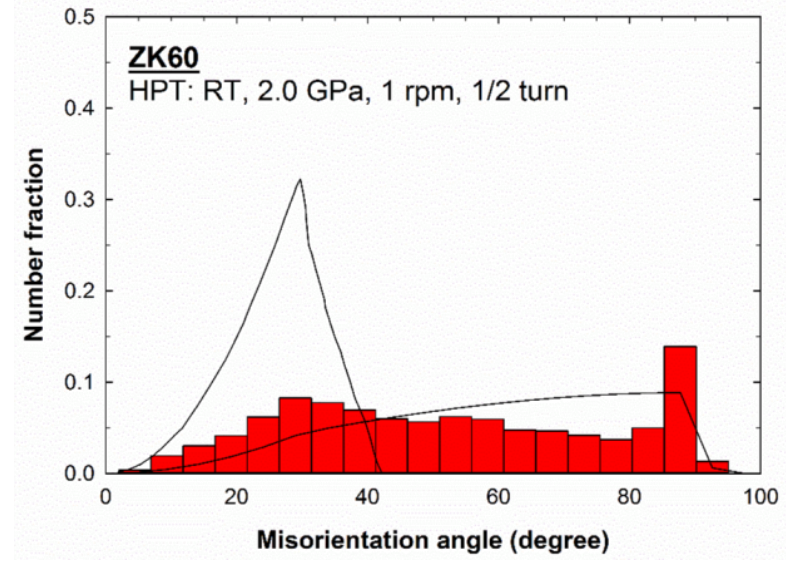

(b)

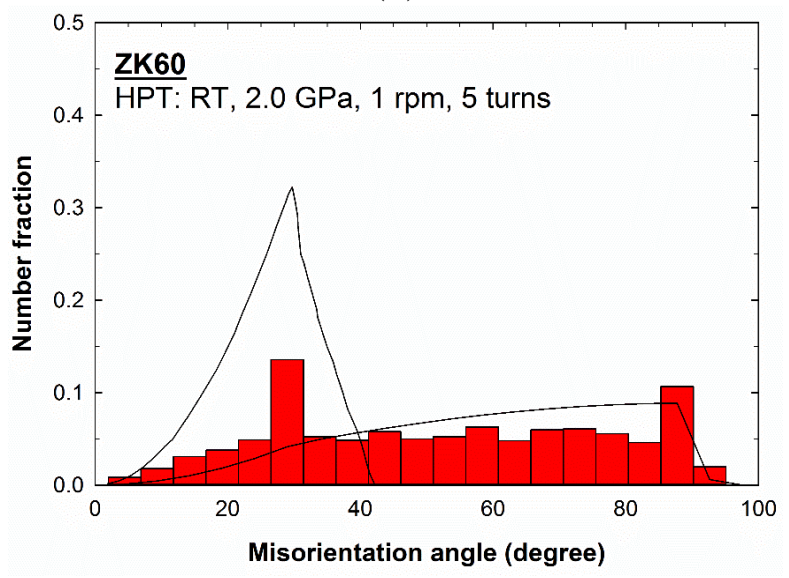

(d)

Fig. 4 

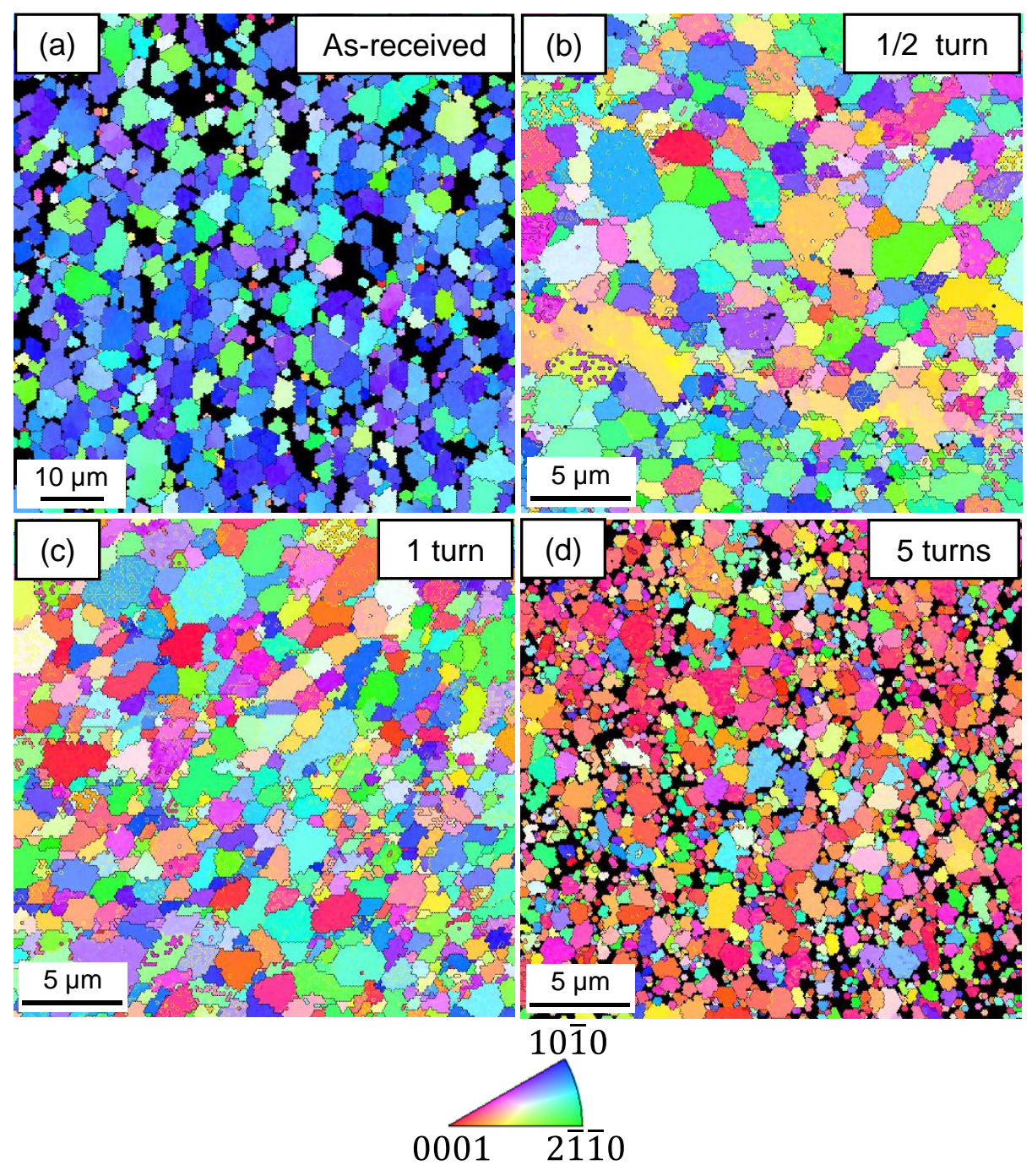

Fig. 5 


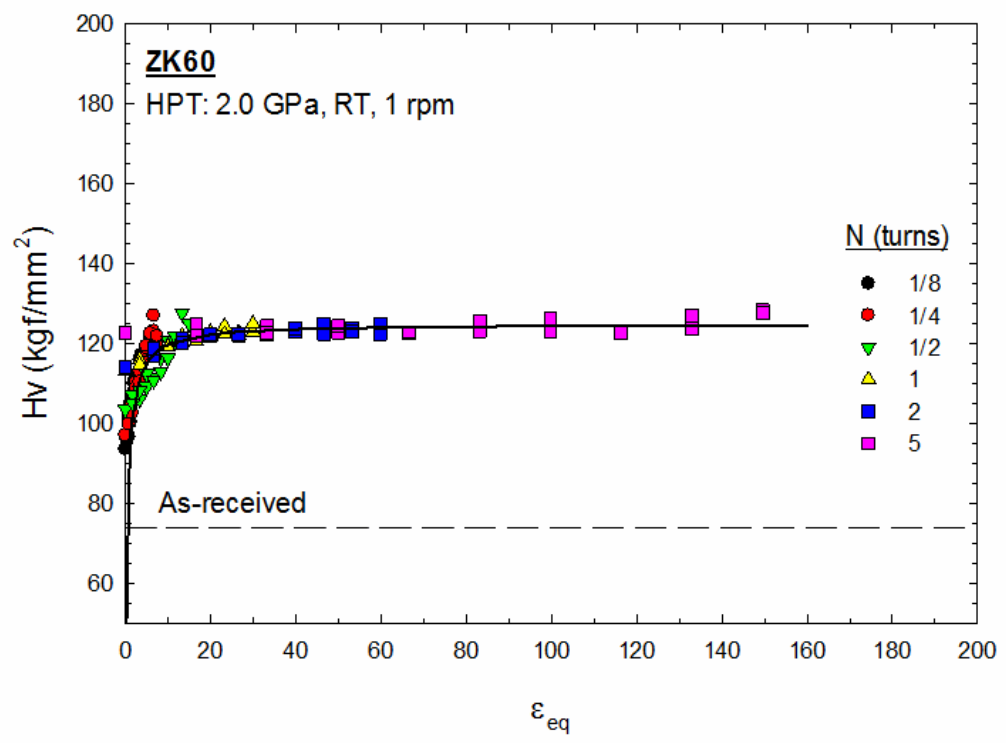

Fig. 7 

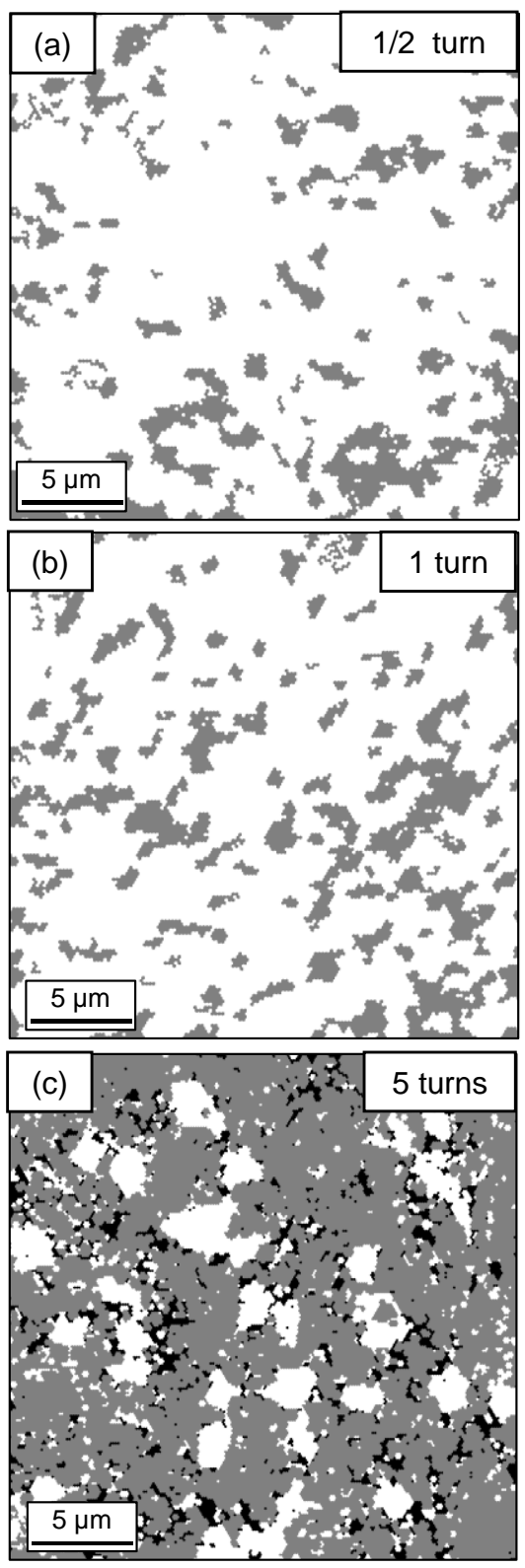

Fig. 8

$$
\text { . }
$$

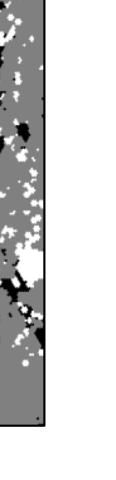




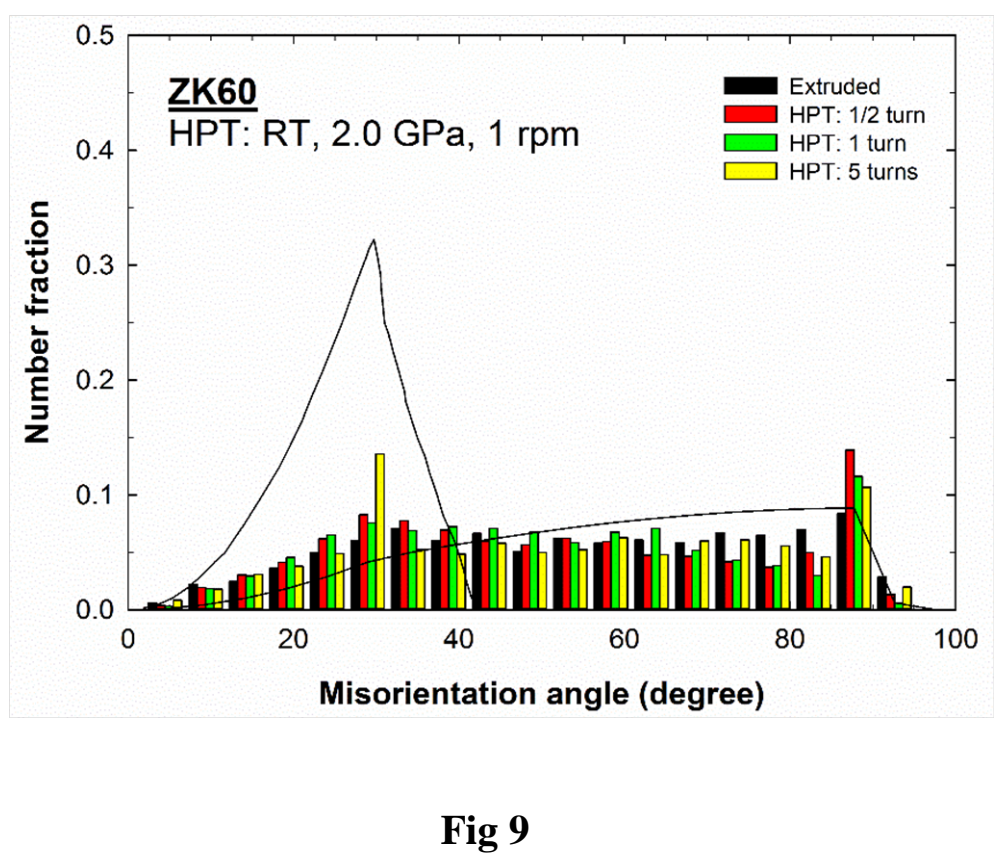

Fig 9

Figure

(20)

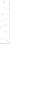

Fure

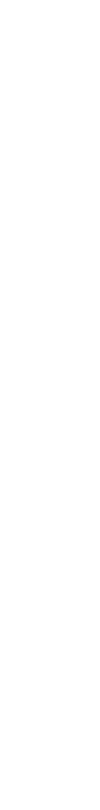




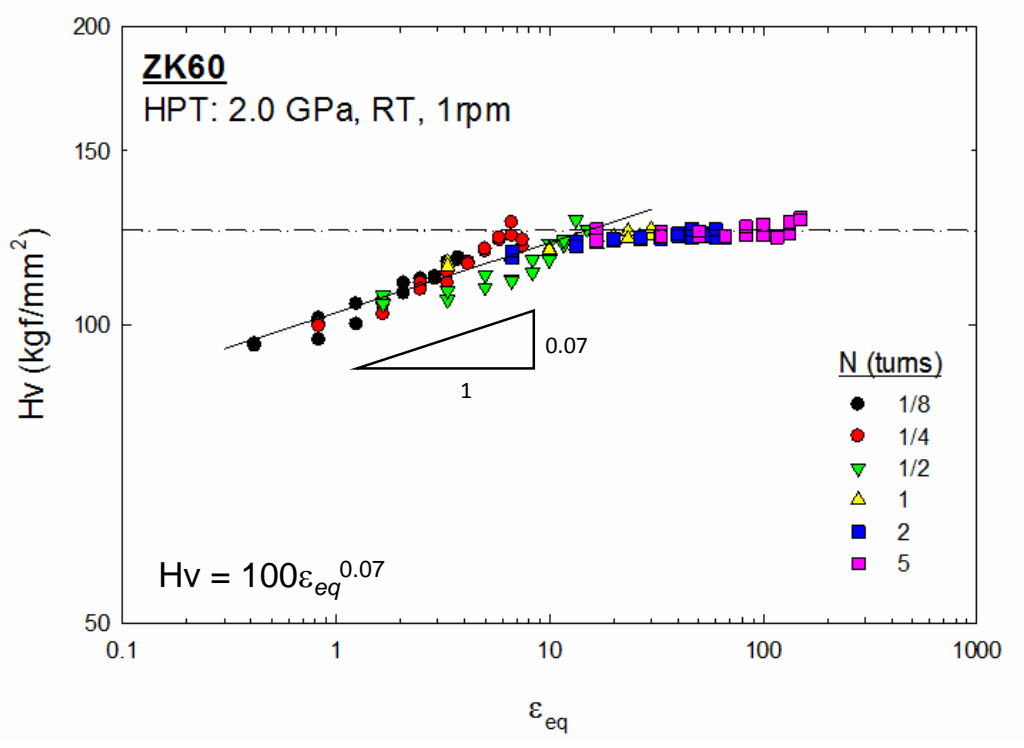

Fig. 10

Figure

Figu

10

$$
\text { -". }
$$

HPT:

$\mathrm{Hv}=100 \varepsilon_{e q}{ }^{0.07}$
1
$1 . ., w$
1

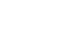

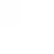

Fig. 10 